\title{
Diálogo con las Bases para el plan de nación "Las sociedades prósperas son las que existen en función del ser humano"1
}

\author{
Departamento de Economía
}

\begin{abstract}
Resumen
Este artículo constituye una reflexión crítica sobre algunos aspectos del documento Bases para el plan de nación. Integra una amplia gama de problemas y desafíos inmersos en los niveles político, cultural, socioeconómico, de participación democrática e institucional del Estado. Destaca la importancia de la planificación, que debe entenderse como el ejercicio concertado y participado entre la administración pública y los representantes, empresariales y laborales, de los sectores productivos. Entonces, un objetivo clave es la "concertación" nacional, el cual no puede lograrse sin la autocrítica. Los modelos económicos actuales han impedido el avance paralelo del crecimiento económico y del desarrollo humano sostenible, de allí la necesidad de una planeación concertada cuyo objetivo principal sea: la nación.
\end{abstract}

\section{Introducción}

El presente artículo es un esfuerzo del Departamento de Economía por reflexionar críticamente sobre algunos de los aspectos socioeconómicos que contiene el documento Bases para el plan de nación. El artículo está dividido en cinco partes.
La primera parte contiene un prefacio al plan de nación que analiza los efectos del proceso de globalización en la identidad nacional, la planeación nacional y los Estados nacionales. La segunda parte estudia los efectos del neoliberalismo y los programas de ajuste en el problema de la po-

1. Este artículo fue elaborado por el Departamento de Economía de la UCA: Francisco Javier Ibisate S.J., Aquiles Montoya, Gerardo Olano, Rafael Antonio Pleitez y Sonia Ivett Sánchez. 
breza estructural. La tercera parte estudia los principales desalíos cconómicos que enfrenta nuestro país para alcanzar un desarrollo humano sosteniblc. La cuarta parte analiza la orientación de las funciones del Estado y el manejo de la política social. La quinta parte trata sobre el desafío de integrar a la microempresa y a las unidades de producción comunitaria al desarrollo económico nacional.

A manera de conclusión se destaca que las $B a$ ses para el plan de nación gana en interés y prolundidad si lo enmarcamos en el entorno mundial del final de siglo. Nuestro problema nacional de pobreza estructural es al mismo tiempo continental y mundial. Al final del siglo XX enfrentamos un problema heredado del siglo XIX: el darwinismo social. Los modelos económicos en boga han cortado el puente entre el crecimiento económico y el desarrollo humano sostenible. El documento, al señalar los grandes desalíos que enfrenta el país, destaca la necesidad de una planeación concertada que tenga como objetivo final: la nación. Y lo más esencial de la nación son los scres humanos y la naturaleza, que han sido las dos víclimas de los modelos económicos en boga. Invitamos a dialogar con las Bases para el plan de nación desde el logotipo de la Cumbre Social, que se realizó en Copenhague en 1995: "las sociedades prósperas son las que existen en función del ser humano".

\section{Un prefacio al Plan de nación}

Un preámbulo natural a las Bases son los discursos del presidente - 1 de mayo y 1 de junio 1997 - al anunciar la comisión que redactaría el presente documento. ¿Qué razones motivaron que el discurso presidencial calificara como nueva etapa histórica la propuesta de un Plan Nacional de Desarrollo? El párrafo introductorio lo explica "como resultado de la voluntad soberana que el pueblo salvadoreño expresó en las pasadas elecciones, dando a las fuerzas políticas el mandato de la concertación para avanzar de la paz al desarrollo integral de nuestro país" (El Diario de Hoy, 1 de mayo 1997). El Plan Nacional de Desarrollo nace desde abajo, por expresa voluntad popular, manifestada en el proceso electoral, y se define como una "concertación".

Daría la impresión que el gobierno anuncia un cambio de agujas en la dirección de la economía. En marzo de 1989, el primer gobierno-ARENA proponía cuatro postulados económicos como los principios de una sociedad libre: (1) la propiedad privada es condición necesaria para la eficiencia de la producción; (2) el mercado libre asegura la mejor asignación de los recursos; (3) la competencia garantiza el funcionamiento del mercado; (4) el Estado tiene una función subsidiaria. Nueve años después, el discurso presidencial, atendiendo a la voluntad soberana del pueblo, hace una evaluación implícita o explícita de aquellos principios económicos.

Se recomienda "la formulación de un Plan Nacional de Desarrollo, con una visión de mediano y largo plazo, que nos lleve al desarrollo y genere estabilidad y confianza" (Item, I de mayo 1997). "Necesitamos tener una visión de largo plazo para dar estabilidad y continuidad al país, más allá de los períodos de gobierno, a fin de convertir a nuestro país en un lugar atractivo para la inversión y generación de empleo, que eleven el bienestar y calidad de vida de la población" (ítem, 1 de junio 1997).

Litcralmente, estos párrafos combinan el panegírico con una difuminada autocrítica. Aquí hay un panegírico de la planeación cconómica en boca de quienes se manifestaban adversarios de toda planificación que no fuera la del mercado. Sin un plan estratégico, se nos dice, carecemos de una visión de mediano y largo plazo que trace las sendas del desarrollo. Sin un plan se desvanecen la estabilidad, la confianza y la continuidad, confiando el rumbo económico a la improvisación de medidas sorpresivas. Sin un plan no hay indicadores a la inversión, malográndose el empleo y la calidad de vida de la población. Indirectamente se indica que el próximo gobierno debiera regirse por un plan de mediano y largo plazo.

El reverso del panegírico es una difuminada autocrítica de la gestión gubernamental. Un partidogobierno que inicia su mandato derruyendo el Ministerio de Planificación, pareciera querer reconstruirlo en tres días al término de su gestión. No deja de ser algo irónico que la presentación del Plan de nación se tuviera en la sede del Ministerio de Asuntos Exteriores cuando todo el contenido y destino del informe es agenda más propia de un Ministerio de Asuntos Interiores. No sabemos hasta qué punto las intenciones del presidente $y$ del gobiemo eran hacer un panegírico y una autocrítica, pero "lo escrito, escrito está". 


\section{1. ¿Tenemos un Plan?}

Los miembros de la comisión nos dicen que ellos ofrecen unos lineamientos para gestar entre todos un Plan de nación. Seguramente habrá diversas interpretaciones en torno a la pregunta: $i$ tenemos un Plan de nación? Las lecturas serán diferentes porque hace tiempo que carecemos de un plan nacional. Desde esta perspectiva es lícito afirmar que sí nos han dado las bases de un plan de desarrollo nacional. Un plan de desarrollo comienza por describir la situación estructural del punto de partida, tal como lo hiciera, en su primer volumen, el plan de desarrollo 1973-1977. Allí había una descripción suficientemente detallada, había una teoría, es decir, unas bases filosóficas sobre la función del Estado en búsqueda de determinados objetivos; incluso, se proponían algunas reformas estructurales que no recibieron el parabién de los poderes económicos. Algo similar aparecía en la proclama de los jóvenes militares que dieron el golpe de Estado en octubre de 1979.

El presente plan nacional, aunque no reporta cuadros estadísticos, integra una amplia gama de problemas y desafíos inmersos en los niveles político, cultural, socioeconómico, participación democrática e institucional del Estado, que se hallaban dispersos en distintos documentos y propuestas de consenso, aparecidos entre 1993-1997. Hay bases para un plan de desarrollo porque integra en el mismo mosaico cinco esferas interrelacionadas c interdependientes. La monotonía y el economicismo a que nos habían habituado los programas monelario-linancieros del Banco Central de Reserva distan cualitativamente de la integración multipolar del presente esquema de nación.

Cuando se nos recuerda que "el nudo gordiano es la pobreza estructural, que se asienta en la marginación social y en la configuración y funcionamiento del poder político" (p. 7) se están anunciando tópicos cualitativamente diferentes. Como se dirá más adclante, cuando no sólo se distingue sino que se contraponen los conceptos de crecimiento y desarrollo económico se está develando un problema histórico: el crecimiento con desempleo, desigualdad y deterioro ecológico genera mayor subdesarrollo económico. Este sí es un pro- blema mundial, que quedaba oculto bajo los agregados del Producto Interno Bruto, las remesas internacionales netas y los déficits fiscales o comerciales. Digamos que este plan de nación desciende hacia una economía más humana y más humanizante.

Si este plan ha tenido una aceptación bastante generalizada es porque se aproxima a una "utopía", algo que no existe pero que es la norma de lo que debiera existir. Calificarlo de utopía es al mismo tiempo una alabanza y un temible desafío. Recurriendo a una comparación, o tal vez a una exageración, puede tener una suerte parecida a la Perestroika de M. Gorbachov, que recibió grandes alabanzas porque anunciaba una reestructuración radical de la administración política y económica, pero que quedó tronchada por la oposición de los poderes políticos y económicos de la URSS. Se le dio un aparente parabién, pero ninguno de los programas económicos vio la luz del día, y en diciembre de 1991 se firmaba la extinción de la Unión de Repúblicas Socialistas Soviéticas. Los micmbros de la comisión del plan no dicen ni amenazan con nada de esto, pero si las fuerzas políticas no atienden este mandato popular de concertación nacional puede repetirse la historia.

\section{2. ¿El regreso de la planeación?}

Al igual que otras propuestas de consenso, 1993-1997, este Plan de nación presenta una característica que ayuda a reconciliarse con las temidas políticas de planeación nacional. A semejanza de lo que se hizo en Europa occidental, luego de la Segunda Guerra Mundial, la planificación se concibe como un ejercicio concertado y participado entre la administración pública y los representantes, empresariales y laborales, de los sectores productivos, en lo que atañe a la esfera económica. En los otros niveles la participación sería más amplia: "un mandato de concertación". El Iíder de la planeación francesa, Jean Monet, hablaba de "planificación por la saliba": reunirse, exponer, proponer y tratar de convencer ( $E C A, 1996$; pp. 866...). La razón es bien sencilla: las medidas que se imponen autoritariamente ni se aceptan, ni se cumplen. Una planeación debe ser concertada porque 


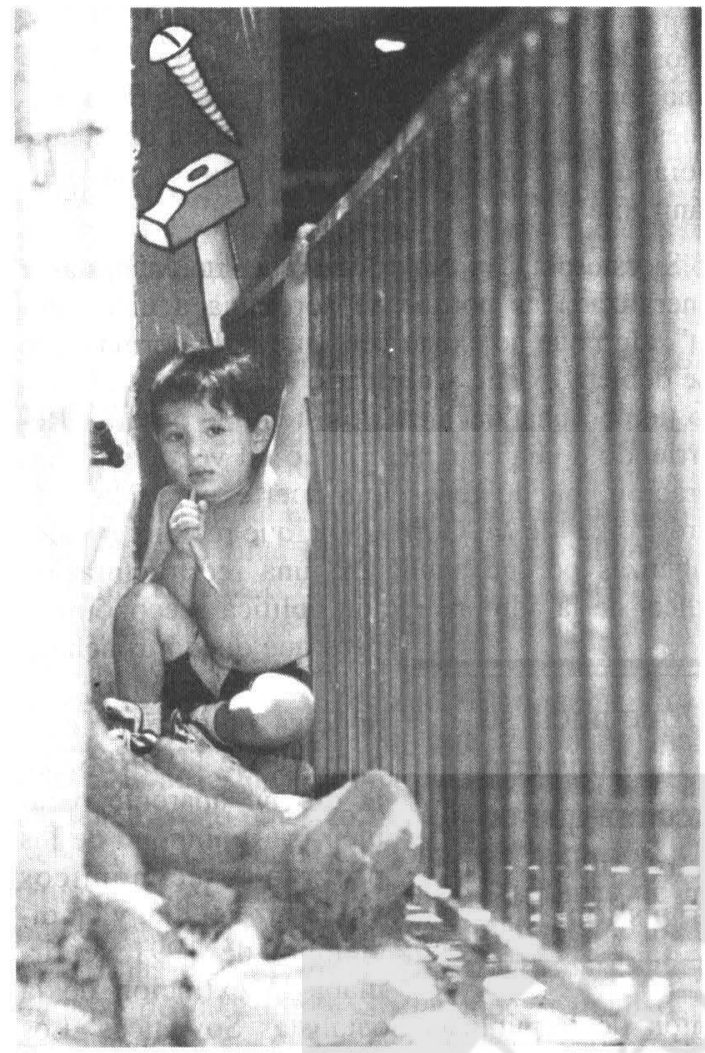

no se pueden alcanzar todos los objetivos simultáneamente. Es menester llegar a acuerdos del mayor bien común y, en otras palabras, hay que convenir en sacrificios presentes en aras de logros futuros más universales. El sacrificio de privilegios e intereses particulares es la traba mayor de cualquier planificación. Nosotros tuvimos una experiencia en $1976 \ldots$ La planeación es concertación y no ventajas competitivas. ¿Es éste el horizonte que nos ofrece el año preelectoral 1998?

\section{3. ¿Nación con globalización?}

La comisión del plan nos ofrece el concepto normal de nación, tal como se celebra en el mes de septiembre, con la laudable postdata de extender las fronteras al istmo centroamericano. El desafío actual es reflexionar sobre la independencia presente. Hablar de nación, de sus valores y tradiciones tiene ahora una transcendencia especial, porque con la globalización neoliberal peligra la misma identidad nacional. La primera sorpresa es que al listar las naciones por el volumen de su producto interno bruto, el país número 15 se llama
General Motors y el 16 Exxon Company... Sin embargo, esta lectura de la nueva clasificación de los países nos puede llevar a un error, si concluimos simplemente que los más grandes dominan a los menores. El verdadero problema mundial es que el concepto de nación y su identidad nacional se ven amenazados hoy día incluso en las naciones más grandes y más desarrolladas. Merece la pena escuchar algunos autorizados testimonios que nos llegan de ambos lados del Atlántico.

El Dr. Maza Zavala (Venezuela) lo expresa en forma contundente al exponer la etapa final de la globalización: "es decir, el mundo como un espacio abierto, el mundo como una totalidad, el mundo como el escenario para un juego estratégico en el cual se abstraen las fronteras, se abstraen los intereses nacionales, y todo se constituye en el juego de las grandes fuerzas del mercado mundial. Esta es la etapa que corresponde al neoliberalismo: abatir las fronteras nacionales. Proteccionismo, no; preferencia al mercado interno, no; planificación nacional, no; regulación de la inversión extranjera, no; soberanía monetaria nacional, no. Apertura, abatimiento de cualquier obstáculo a la movilización de factores, mercancías, capitales, adscripción incondicional a los cambios emergentes de los centros mundiales de desarrollo, totalización del juego estratégico; esto es la etapa de la globalización" ( $E C A, 1997$, p. 389).

Para entender mejor éste y los testimonios siguientes, valga recordar que la globalización integra, al menos, tres inmensos mercados. En primer lugar, la red mundial de las megaempresas, tanto o más poderosas que muchos Estados por tres razones: la magnitud de su cifra de negocios, superior al Producto Interno Bruto de bastantes naciones. La alta y sofisticada tecnología que les confiere una ventaja competitiva frente al resto de las empresas productivas $y$, en consecuencia, un poder de negociación o efecto-dominación frente a los mismos Estados, abatiendo toda clase de fronteras. Todavía es mayor el poder y el volumen de transacciones monetarias realizadas en el mercado financiero. El flujo de dinero movilizado en cuatro días de transacciones de divisas en las bolsas de valores equivale al PIB de Estados Unidos de un año, o al Producto Interno Bruto mundial de un mes (ECA, 1997; p. 806). En tercer lugar, el mercado mundial de la información (medios de comunicación social), cuyos oligopolios nos presentan e imponen su interpretación de los hechos, nos in- 
yectan sus valores y criterios, sus principios mercantilistas (la moneda es el álgebra de toda la actividad humana), al mismo tiempo que desarraiga valores y costumbres tradicionales. Se trata de un lavado de conciencias.

\subsection{Acoso a la identidad nacional}

A este entorno se refiere el segundo testimonio del Dr. Maza Zavala: "Una vez más, la globalización no solamente significa homogeinización del modo de producción en el mundo, sino también uniformidad cultural. Los patrones de comportamiento, los valores, los gustos, los hábitos, todo se mundializa; ya no hay lugar para los valores tradicionales, para los valores que identifican a un pueblo, los valores en que se fundamenta la existencia de una nación, sino que hay lugar para la universalización; pero una universalización que no resulta del consenso, que no resulta de la confluencia de voluntades de las diferentes sociedades humanas, sino que resulta de un designio, de una matriz diseñada para que se ajusten a ella, a su funcionamiento, todas las actividades. Y de allí que haya, por consiguiente, un sistema mundial de información, un sistema mundial de comunicación, un sistema mundial de estilos de vida y, desde lucgo, un sistema polílico mundial: el sistema de la democracia representativa, una manera mundial de entender y aceptar la actividad del hombre, el hombre sin transcendencia, el hombre como sujeto y objeto de las apetencias de la vida ordinaria, el hombre en el afán de lucro y disfrute, el hombre que encuentra en ello el principio y fin de su razón de ser"... (Ibídem, p. 389).

Pasemos a escuchar testimonios que nos llegan desde países desarrollados. En artículo más breve y reciente, Arthur Schlesinger, quien fuera asesor del presidente Jonh F. Kennedy, condensa la devaluación de la identidad nacional: "Un objetivo de la creatividad capitalista es la economía globalizada. Un candidato - no previsto- para la destrucción capitalista es el Estado nacional, tradicional asiento de la democracia. El ordenador convierte el mercado sin trabas en un monstruo global irresistible que atraviesa las fronteras, debilita los poderes nacionales de implementación de impuestos y regulaciones, impide la gestión nacional de las tasas de interés e intercambio, amplía las disparidades de riqueza lo mismo dentro de las naciones que entre ellas, derrumba las normas laborales, degrada el medio ambiente, niega a las naciones el poder de dar forma a su propio destino económico, sin dar cuenta a nadie y crea una economía mundial sin una política mundial. El ciberespacio está más allá del control nacional. No existen autoridades que proporcionen control internacional. ¿Dónde está la democracia?" (Política Exterior, No 60, p. 137).

Frank Hinkelammert vendría a cuestionar el título de Plan de nación en virtud de ciertos comportamientos públicos presentes entre nosotros. "Esta globalización se basa en la libertad de los flujos de mercancías y capitales y en la ausencia de intervenciones estatales $u$ otros en estos flujos. Eso no implica de ninguna manera una ausencia del Estado. La globalización no es posible sin una acción constante y decidida. Sin embargo, los Estados ahora funcionan sobre todo como instancias de la globalización, que debe facilitar los flujos de mercancías y capitales y fomentarlos con subvenciones inmensas y que en tamaño superan la cantidad de subvenciones que el Estado social jamás haya efectuado. Solamente en esta forma se considera la competencia como el verdadero motor de la globalización y la victoria de la competencia como eficiencia" (ECA, 1997, p. 804).

No tenemos la impresión de que se hayan formulado estas interrogantes al presentar los lineamientos del Plan de nación, porque incluso se percibe una espontaneidad en integrarse, con los brazos abiertos, en el proceso de globalización. Por lo menos, no se enfatiza explícitamente que el huracán de la globalización profundiza aún más la pobreza estructural, la marginación y la desigualdad social. Pese a esta difuminación de la realidad mundial, se legitima totalmente el presentar y defender un Plan de nación, si escuchamos otros testimonios de países desarrollados.

\subsection{En defensa de la identidad nacional}

Si alguien conoce el funcionamiento de la globalización y de los mercados financieros, tal persona es George Soros, que ha lucrado una inmensa fortuna en los 40 años de trabajo en los mercados financieros y que se ha convertido en uno de los famosos filántropos. Tal vez su filantropía nace de cierto remordimiento de conciencia, convertido en uno de los grandes críticos de la economía mundial. En su artículo, "Hacia una sociedad abierta global", comenta cinco tipos de deficiencias en el sistema capitalista global. En razón de la brevedad se extraen unos párrafos de la cuarta y quinta deficiencias. 
"4. ¿A quién corresponde evitar una concentración de poder indebido y salvaguardar la estabilidad? Esto me lleva al papel del Estado. Desde el final de la II Guerra Mundial, el Estado ha desempeñado un papel creciente en el mantenimiento de la estabilidad económica, y se ha esforzado por garantizar la igualdad de oportunidades y proporcionar una red de seguridad social, especialmente en las naciones altamente industrializadas de Europa y América del Norte. Pero la capacidad del Estado para ocuparse del bienestar de sus ciudadanos se ha visto gravemente afectada por la globalización, debido a que el capital puede escapar a la fiscalización mucho más fácilmente que el trabajo. El capital tiende a evitar países donde el empleo se vea sometido a impuestos elevados o esté muy protegido. Ello conduce a un aumento del desempleo, que es lo que ha sucedido en Europa continental. No estoy defendiendo los anticuados sistemas europeos de seguridad social, que necesitan urgentemente una reforma, pero me preocupa la reducción de las prestaciones sociales tanto en Europa como en América"...

"5. Esto me lleva al problema más confuso: el de los valores y la cohesión social. Toda sociedad necesita tener valores compartidos. Los valores del mercado no sirven para este propósito porque sólo reflejan lo que un participante en el mercado está dispuesto a pagar a otro dentro de un libre intercambio. Los mercados reducen todo, incluidos los seres humanos (mano de obra) y naturales (tierra) a mercancía. Podemos tener una economía de mercado, pero no podemos tener una sociedad de mercado. Además de los mercados, la sociedad necesita instituciones que sirvan a fines sociales como la libertad política y la justicia social. Esas instituciones existen en países concretos, pero no en la sociedad global. El desarrollo de una sociedad global se ha quedado retrasado respecto al de una economía global. A menos que se acabe con esa distancia, el sistema capitalista global no sobrevivirá" (El País, 23 diciembre 1997).

Desde similar perspectiva, A. Schlesinger hace unas reflexiones medio proféticas. "El mundo de hoy está desgarrado en direcciones opuestas. La globalización ocupa el puesto de mando y dirige a la humanidad, pero - al mismo tiempo- impulsa a las personas a buscar refugio frente a sus poderosas fuerzas, que están más allá de su control y comprensión. Se retiran a unidades familiares, inteligibles, protectoras. Ansían la política de la identidad. Cuanto más rápidamente se integra el mundo, más personas se refugiarán en sus enclaves religiosos, étnicos o tribales. La integración y la desintegración se alimentan mutuamente".

Junto a la resistencia pasiva es previsible esperar reacciones de rechazo y enfrentamiento. "El capitalismo también seguirá dando bandazos, pero la ideología del laissez-faire probablemente se desvanecerá cuando los capitalistas descubran la serie de perturbaciones que el mercado $\sin$ trabas no puede resolver o incluso agravar. El capitalismo salvaje, con salarios bajos, jornada larga y trabajadores explotados, provoca el resentimiento social, resucita la guerra de clases y da nueva vida al marxismo. Para avanzar por senderos constructivos, el capitalismo debe subordinar los planes y beneficios a corto plazo a necesidades sociales de largo plazo, como las inversiones en educación, investigación y desarrollo, protección del medio ambiente, ampliación de la sanidad, rehabilitación de infraestructuras y recuperación de las ciudades. No es probable que los capitalistas lo hagan por sí mismos. Las perspectivas de largo plazo exigen una dirección pública". Estas reflexiones nos llegan de un asesor presidencial de Estados Unidos.

Alain Tourraine, Director del Instituto de Estudios Superiores de París, repite la pregunta y complementa la respuesta. "Pero, ¿quién puede ejercer este control cuando se nos repite constantemente que los Estados nacionales han perdido su poder y se han vuelto impotentes frente a la mundialización de los mercados? Esta afirmación exige dos respuestas. La primera que esto es falso en gran medida. Cuanto más compleja es una economía, más difícil es lograr un crecimiento duradero, y la importancia de esta idea proviene de que muestra hasta qué punto los equilibrios internos se han convertido en condiciones necesarias para el crecimiento de una economía. Estos equilibrios sociales no se mantienen espontáneamente; al contrario, 
la economía de mercado crea desequilibrios y luerzas de acumulación y de exclusión que amenazan a los equilibrios básicos de la sociedad. Estos, para ser restablecidos, requieren la intervención del Estado y de otros agentes propiamente políti$\cos y$ sociales.

La segunda respuesta es que los centros políticos de decisión sólo pucden luchar contra ciertas consecuencias de la economía de mercado si son forzados a intervenir por demandas sociales organizadas, que sc expresan por la vía electoral, a través de los medios de comunicación y, más directamente aún, bajo la forma de movimientos sociales organizados. Desde hace algunos años vemos aumentar en Europa occidental el número de gobiernos de centro-izquierda. Actualmente, sólo Alemania y España permanecen alejados de este modelo dominante. La misma tendencia se manifiesta en los grandes países de América Latina, como México, que ha elegido a Cárdenas para la alcaldía de la ciudad de México, o Argentina, donde la candidatura de Frepaso, partido de izquierda, ha obtenido la alcaldía de Buenos Aires, e incluso Chile, donde el candidato mejor situado para la próxima elección presidencial es el jefe de un partido de izquierda"...(El País, 10 diciembre 1997).

Esta sumatoria de textos vienen a legitimar el esfucrzo por diseñar un Plan de nación. Esto no significa una exaltación de las fronteras, de las aduanas, de los ejércitos, del proteccionismo por compadrazgo, y menos aún del nacionalismo étnico, la xenolobia o los fundamentalismos religiosos, que tapizan nuestro mundo. Por supuesto, un Plan de nación está a favor del necesario intercambio comercial, de los avances lecno-

lógicos, de la apertura a otras culturas y modelos económicos. Como lo indica la comisión del plan, nuestra nación se realiza con la intcgración centroamericana. Plan de nación significa que la globalización gira sobre sí misma y muestra todas sus caras y aristas. Nos oponemos a su materialismo mercantil que reduce a las personas a moneda y mercancía, a su lógica financista que sacrifica el futuro de la humanidad y de la naturaleza en aras del lucro presente, a sus monopolios de comunicación que deslavan los mejores valores nacionales, a su irrespeto a los Estados, a quienes convierten en sus agentes de tránsito.
Incluso le sugerimos al neoliberalismo: "haga su autocrítica" (Realidad, enero, 1998). Al fin y al cabo, para que las empresas sobrevivan es menester que la humanidad viva.

\subsection{Un Estado para una nación}

Hace nueve años, el Plan de Desarrollo Nacional 1989-1994 calcaba sus principios filosóficos y económicos de una publicación de FUSADES: "Hacia una economía de mercado: bases para una nueva estrategia de desarrollo económico y social" (mayo, 1989). El quinto principio filosófico y cuarto postulado económico rezaban el mismo estribillo: el Estado desempeña un papel subsidiario. Con los giros que viene dando la globalización pocos estarán de acuerdo en encerrar al Estado en la garita de la "subsidiaridad". Con esta intención hemos recopilado esos autorizados testimonios desde ambos lados del Atlántico.

\section{¿Discusión doctrinaria?}

El Plan de nación dedica un acápite a la redefinición del rol de Estado. Por tratarse de "una discusión de carácter idcológico y doctrinario" se solicita abordar con claridad el tema para llegar a un acuerdo nacional (No 16). La redacción de este acápite (pp. 22-24) parece dar cabida a las distintas posiciones docirinarias; los mismos textos pueden leerse con distinta lente. Dos textos, a modo de ejemplo. "La naturaleza del Estado como regulador, subsidiario, garante o gestor está en juego en este debate, que debe situarse en una dimensión constructiva en función de la necesaria modernización del Estado salvadoreño" (No 19). "El Estado 
debe asegurar ciertamente, la estabilidad macroeconómica y las condiciones necesarias para que el sector privado desarrolle una oferta ampliada y accesible de vivienda, empleo y servicios básicos. Pero no puede limitarse a esto. También debe actuar de manera directa y programática para superar los desequilibrios históricos en el acceso de los diversos sectores a bienes y servicios básicos para una vida digna" (No 20). Estos textos se parecen a una autopista de muchas vías, donde unos querrán rodar por los carriles de las derechas y otros por los carriles de las izquierdas .

En orden a llegar a un consenso se pueden adelantar algunas primeras impresiones. Repasando todos los roles y funciones del Estado, parece que la subsidiaridad no es el rasgo típico que deba caracterizar al Estado moderno. Permanece aún cierto resabio maquiavélico de acuerdo al cual "la necesaria modernización" sólo se aplica al Estado o sector público; ésta es una verdad parcial, porque un análisis sereno de la economía salvadoreña nos muestra que también el sector privado está hecho de la misma leña $(E C A, 1997$, pp. 799-817). Ya es hora de que recordemos a muchos neoliberales que el problema no es sólo el Estado: las grandes perturbaciones mundiales emanan de las bolsas de valores (octubre, 1997), por virtud $y$ gracia de decisiones tomadas por importantes bancos y empresas privadas, amén de especuladores privados. Hoy día no se puede culpar a las políticas estatales de tal inestabilidad general, cuando es el mercado financiero quien impone sus políticas a los Estados. Algo semejante está sucediendo a nivel nacional.

Además, el debate se centra en el propio concepto de modernización a lo liberal. Algo valen al respecto los testimonios de Maza Zavala, A. Schlesinger, G. Soros y A. Tourraine... Es importante que se insista en los amplios servicios que el sector público debe prestar para el desarrollo del sector privado, porque esto significa más que subsidiaridad: pero no se enfatiza en la misma forma en los servicios fiscales con que el sector privado debe financiar los servicios públicos; más directamente, es muy tímida la referencia a la reforma de la estructura fiscal.
Uno de los textos citados puede orientar la reflexión sobre las funciones del Estado. "También debe actuar de manera más directa y programática, para superar los desequilibrios históricos en el acceso de los diversos sectores a bienes y servicios básicos para una vida digna". Este párrafo engarza con el nudo gordiano de nuestra economía: la pobreza estructural, que se asienta en la marginación sociocultural y en la configuración y el funcionamiento tradicional del poder político (p. 5). Engarza también con el ideario de la cumbre de Copenhague, 1995.

\subsection{Respuesta histórica: "las sociedades próspe- ras son las que existen en función del ser humano"}

Este era el logotipo de la Cumbre Mundial sobre el Desarrollo Social. Los documentos de antecedentes mostraban tres grandes problemas: se generaliza la pobreza, el crecimiento con desempleo y la atomización o insolidaridad social. Este logotipo enfrenta a los Estados con tres problemas: el humano de la pobreza, el económico del desempleo y el social de la insolidaridad. Es claro que este logotipo no coincide con otros conceptos de modernización, concretamente con los aplicados a la restricción del espacio y funciones públicas, a la privatización de sus activos, a la sola función de subsidiaridad, a la simple tecnificación de la administración pública y a la reducción de sus puestos de trabajo. Por supuesto que también hay que dedicar tiempo a estos problemas por ser muy importantes.

El logotipo de Copenhague nos centra en el eje de la modernización. El ser humano es lo más moderno que existe, precisamente porque es lo más antiguo. El ser humano siempre ha sido moderno o moderno a medias, porque el ser humano siempre ha estado presente, pero ni antes ni ahora ha sido tratado, en sus mayorías, como ser humano. Este ha sido el problema siempre moderno en la historia de la humanidad. No inventemos otra modernización. Ahora lo redescubrimos al enfatizar el desarrollo del capital humano, a condición de no pervertir esta expresión haciendo del hombre 
una nueva servidumbre de la revolución tecnológica. Parece que esto vuelve a suceder.

\section{Problemas de la revolución informática}

Aunque este tema se tratará más ampliamente en otro artículo de próxima aparición en esta revista, adelantaremos dos breves referencias. Escuchamos de nuevo a A. Schlesinger: "El mundo informatizado plantea problemas a la democracia. Mientras la revolución industrial creó más puestos de trabajo de los que destruyó, la revolución informática amenaza con destruir más puestos de los que crea. Amenaza también con levantar nuevas y rígidas barreras de clase, especialmente entre los instruidos y no instruidos. La desigualdad económica ha aumentado ya en Estados Unidos hasta el punto de que son mayores las disparidades en el igualitario Estados Unidos que en las sociedades clasistas de Europa. Felix Rohatyn, el banquero de inversiones que rescató de la bancarrota a la ciudad de Nueva York, habla de las tremendas transferencias de riqueza desde los trabajadores de baja capacitación y clase media a los propietarios de los bienes de capital y a la nueva aristocracia tecnológica".

Desde Francia, A. Tourraine se expresa incluso con mayor dureza: "El descontento, la inquietud y la protesta se hacen oír de nuevo. ¿Cómo podía ser de otro modo cuando la parte del producto nacional que va a los asalariados ha disminuido masivamente - alrededor de un 10 por ciento - tanto en Alemania como en Francia, y cuando el salario real de los trabajadores menos cualificados ha disminuido en Estados Unidos, aunque este país está experimentando éxitos cconómicos sin precedentes?... Nadie puede desear que se ensanche el abismo que separa ya al mundo económico de los mundos político o cultural. Por tanto, es necesario hacer lo posible para que se forme una voluntad colectiva que ponga fin al desarrollo sin freno del capitalismo, es decir, de la economía de mercado, mientras rechace todo control político y social de sus actividades. Hay que restablecer el control de los medios económicos para las finalidades políticas y sociales... La tormenta se escucha casi por todas partes, excepto en Estados Unidos, y en todos los países, incluido Estados Unidos, aumenta el temor de una crisis económica grave que incrementará la pobreza, la desigualdad y la exclusión de una manera insoportable. El largo silencio de la época neoliberal debe terminar y el debate público sobre los fines y los medios de la economía debe revivir. No perdamos más tiempo" (El País, 10 de diciembre de 1997).

\subsection{Nostalgia de un Estado de bienestar}

Se entiende porqué en Europa, y vale para nosotros, se estén realizando encuentros internacionales sobre el Estado de bienestar. En la filosofía del Estado social de bienestar se define al Estado como un creador de valores. Estos valores se centran en las consignas de lihertad, igualdad y fraternidad. Se trata de la libertad-real, "cuya idea nuclear es que sólo mediante la remoción de los obstáculos de carácter económico y social, lograrán los individuos ser realmente libres". La libertad se conecta esencialmente con la capacidad económica que conduce al Estado a la prosecución no sólo de los derechos legales y autonomía, sino también de los derechos económicos y sociales. La libertad real exige una real igualdad. "MienIras que la igualdad liberal conduce a un Estado abstencionista (todos somos iguales ante la ley), la formulación democrática de la igualdad conduce a un Estado social, comprometido con el bienestar y el disfrute de los derechos económicos y sociales".

Por lo que toca a la fraternidad, se trata de un término ausente en el diccionario liberal, e incluso cuestionado por su filosofía política; mientras que el Estado social no deja a los individuos abandonados a su propia suerte. La idea de fraternidad "niega la concepción de la sociedad como un mero agregado de individuos, pero critica también aquellas otras concepciones que anulan al individuo disolviéndolo en la sociedad". Libertad y dignidad del individuo, junto con la defensa del interés común. "La idea de fralernidad servía para justificar la idea de obligaciones positivas entre los individuos y, por ende, de éstos hacia la sociedad y de ésta hacia aquellos" (ECA, 1996; pp. 867-868). Similar doctrina nos ofrece Juan Pablo II en su reciente mensaje: "De la justicia de cada uno nace la paz para todos". El Papa (polaco) combina el término fraternidad con el concepto de "solidaridad".

\section{Modernización de la historia}

También los Estados deben modernizarse y dehen modernizar la historia. La modernización del Estado significa la readecuación organizativa y de su personal administrativo a las funciones que le está demandando la cambiante historia. Es la historia nacional, regional y mundial quien determina 
sus funciones y responsabilidades. Un Estado moderno es el que en cada momento acompaña y camina con la nación. Sus funciones emanan de los problemas de la nación y su principal función es conocer esta realidad problemática para proponer y concertar soluciones. Este parece ser el pensamiento latente en los redactores del Plan de nación. La modernización es una responsabilidad dependiente de cada historia. La dificultad radica en que la historia cambia en cada país a lo largo del tiempo y también son diferentes las historias en las distintas naciones y continentes. Por lo tanto, no puede haber un único modelo de Estado moderno. Hay que leer los signos de los tiempos.

Si a lo largo del siglo XX ha habido dos fases de modernización estatal, la primera de ensanchamiento $\mathrm{y}$ ampliación de funciones (1930-1970...), la segunda de su reducción y reconversión (1970...), al terminar el milenio volvemos a entrar en una fase de evaluación, incluso de un renovado y tenso debate sobre el papel y responsabilidades del Estado ( $E C A$, No $567-568,1996$, pp. 62...). Por una parte, la mundialización económica y sus medios publicitarios reducen los márgenes de acción de los gobiernos nacionales y, por otra parte, la misma globalización, al reproducir los problemas de marginación social y exclusión económica, junto con el deterioro de los valores éticos y nacionales, vuclve a reclamar la presencia activa del Estado. No se trata de un proceso de clonación, que reproduce los mismos gobiernos y los mismos Eslados, porque volveríamos a las mismas crisis. Se trata de un proceso de reconversión de acuerdo con los reclamos de la historia que, de acuerdo con los testimonios leídos desde países adelantados, parece aconsejar un actualizado Estado social de bienestar.

\section{EI nudo gordiano: "la pobreza estructural"}

Uno de los temas introductorios que seguramente se presta a debate es la raíz histórica del "nudo gordiano" o "nudo crucial". En el Plan de nación, el nudo crucial es la pobreza estructural que se asienta en una realidad más profunda, la marginación sociocultural, que deriva a su vez de la configuración y funcionamiento tradicional del poder político. Este nudo crucial penetraría los cincos niveles: político, cultural-educativo, socioeconómico, participación ciudadana y lo institucional del Estado. Sin embargo, el plan nacional es algo tímido en señalar un elemento constitutivo de la pobreza estructural, y es la riqueza-estructural. Son dos elementos complementarios de la misma realidad, a la cual hay que buscar un origen común. Los testimonios antes citados, desde países desarrollados, muestran que también en la presente década cohabitan ambos efectos estructurales en un entorno de capitalismo global.

Respecto al nudo crucial vale la advertencia que se nos hace en el acápite de la redefinición del rol de Estado: por tratarse de una discusión de carácter ideológico y doctrinario, se solicita abordar con claridad el tema para llegar a un acuerdo nacional (No 16). Ahora bien, la claridad sólo puede nacer de la observación e interpretación histórica, a sabiendas del peligro de leer dicha historia desde la propia ideología doctrinaria. Con miras a romper este círculo vicioso se propone escuchar las reflexiones vertidas en un estudio titulado: "El neoliberalismo en América Latina" (México, noviembre, 1996). El documento viene firmado por los dieciocho superiores provinciales de la Compañía de Jesús de Latinoamérica. Debajo de estas firmas están los análisis de académicos, teólogos y pastoralistas. Este documento nos da una visión continental sobre los mismos acápites del Plan de nación. El texto puede lcerse en la revista Realidad, No 54, diciembre, 1996.

\subsection{El nudo gordiano: el liberalismo en Améri- ca Latina}

He aquí algunos párrafos, sin más comentario. "Nos resistimos a aceptar tranquilamente que las medidas económicas aplicadas en los últimos años, en todos los países latinoamericanos y del Caribe, sean la única manera posible de orientar la economía y que el empobrecimicnto de millones de latinoamericanos sea un costo irremediable de un futuro crecimiento. Los comportamientos económicos y políticos a los que nos referimos refle- 
jan, en el ámbito público, los límites y contravalores de una cultura inspirada en una concepción de la persona y de la sociedad ajena a los valores del Evangelio.

Desde esta perspectiva hemos contemplado el desarrollo de nuestros pueblos en los últimos años. Vemos que en la década de los ochenta el proceso de ajuste necesario para reorganizar las economías, superar el déficit fiscal y de balanza de pagos, pagar la deuda y recuperar el crecimiento, golpeó tremendamente a las mayorías populares de todos nuestros países. Después de los años noventa, al madurar el ajuste y la apertura, se esperaba que concluyeran los tiempos difíciles. Pero vemos que no ha sido así, a pesar de que se ha dado un crecimiento moderado. Hay un sentimiento muy generalizado en los sectores populares y pobres de pérdida en la calidad de vida y existen evidencias contundentes del deterioro de la distribución del ingreso. Aumenta la protesta ciudadana y en algunos lugares ha vuelto a aparecer con fuerza la lucha armada como invitación a un cambio profundo de la situación.

La desigualdad, la miseria y la corrupción, que son los tres grandes motivos de descontento general, están presentes y en no pocos aspectos se han agravado. Allí están en la pobreza 180 millones de hermanos y hermanas nuestros, y en la miseria 80 millones. Sabemos que este problema tiene una larga historia de modelos de crecimiento desigual y de desarrollo excluyente, donde al lado de grupos muy ricos y de una clase media importante, multitudes inmensas han quedado por fuera de una vida humana digna. Vemos que en los últimos años esta situación tiene detrás una manera de dirigir la economía, llamada neoliberalismo, que además penetra la política y toda la vida social.

La injusticia estructural del mundo tiene sus raíces en el sistema de valores de una cultura moderna, que está haciendo impacto mundial. Ese impacto llega a nuestros países a través de la tecnología y de los sistemas financieros internacionales. Este impacto cultural, al radicalizarse por el neoliberalismo, tiende a valorar al ser humano por su capacidad de generar ingresos y de tener éxito en los mercados. Con este contenido reduccionista penetra en los dirigentes de nuestros países, atraviesa la clase media y llega hasta los últimos reductos de las comunidades populares, indígenas y campesinas, destruyendo la solidaridad y desatando la violencia. Este mercado absoluto no acepta regulaciones en ningún campo. Es libre. sin restricciones financieras, laborales, tecnológicas o administrativas".

\subsection{Claroscuros del neoliberalismo}

Por lo tanto, el neoliberalismo no es igual a la economía, que reconoce la importancia del mercado de todos los bienes y servicios sin absolutizarlo, ni es igual a la democracia liberal. Oponerse al liberalismo no significa estar en contra de la utilización eficiente de los recursos de que dispone la sociedad; no significa delimitar la libertad individual; no significa apoyar el socialismo de Estado. No se nos escapan los elementos positivos de la movilización internacional llevada a cabo por las transformaciones tecnológicas, que han permitido disminuir las enfermedades, facilitar las comunicaciones, acrecentar el tiempo disponible para el ocio y la vida interior, hacer más cómoda la vida en los hogares...

Pero estos elementos están lejos de compensar los inmensos desequilibrios y perturbaciones que causa el neoliberalismo, en términos de multiplicación de masas urbanas sin trabajo o que subsisten en empleos inestables y poco productivos; quiebra de miles de pequeñas y medianas empresas, destruccción y desplazamiento de poblaciones indígenas y campesinas, expansión del narcotráfico basada en sectores rurales, cuyos productos tradicionales quedan fuera de competencia; desaparición de la seguridad alimentaria; aumento de la criminalidad, empujada no pocas veces por el hambre; desestabilización de las economías nacionales por lo flujos libres de la especulación internacional; desajustes en comunidades locales por 
proyectos de multinacionales que prescinden de los pobladores.

Pero igualmente vemos los aspectos de estos procesos que disminuyen al hombre y a la mujer, particularmente en el contexto de la radicalización neoliberal, porque - pretendiéndolo o no- desatan la carrera por poseer y consumir, exacerban el individualismo y la competencia, llevan al olvido de la comunidad y producen la destrucción de la integridad de la creación.

\subsection{Limites de las políticas de ajuste}

El neoliberalismo se manifiesta en sus políticas de ajuste y apertura que, con diversas connotaciones, se aplican en los países latinoamericanos. Estas ponen el crecimiento económico -y no la plenitud de todos los hombres y mujeres en armonía con la creación- como razón de ser de toda la economía. Restringen la intervención del Estado hasta despojarlo de la responsabilidad de garantizar los bienes mínimos que se merece todo ciudadano por ser persona. Eliminan los programas generales de creación de oportunidades para todos y los sustituyen por apoyos ocasionales a grupos focalizados. Privatizan empresas con el criterio de que la administración privada es mejor en último término para todos. Abren sin restricciones las fronteras para mercancías, capitales y flujos financieros y dejan sin suficiente prolección a los productores más pequeños y débiles. Hacen silencio sobre el problema de la deuda externa, cuyo pago obliga a recortar drásticamente la inversión social.

Subordinan la complejidad de la hacienda pública al ajuste de las variables macroeconómicas: presupuesto fiscal equilibrado, reducción de la inflación y balanza de pagos estable; pretendiendo que de ahí se sigue todo bien común en el largo plazo, y sin atender los mayores problemas de la población que emergen de estos ajustes y que tienen que ser atendidos simultáneamente por una política de Estado.

Insisten en que estos ajustes producirán un crecimiento que, cuando sea voluminoso, elevará los niveles de ingreso y resolverá por rebalse la situación de los desfavorecidos. Para incentivar la inversión privada eliminan los obstáculos que podrían imponer las legislaciones que protegen a los obreros. Liberan de impuestos y de las obligaciones con el medio ambiente a grupos poderosos, y los protegen para acelerar el proceso de industria- lización. Así provocan una concentración todavía mayor de la riqueza y del poder económico...

\subsection{Factores y efectos estructurales}

El neoliberalismo produce efectos estructurales que generan pobreza. Estos factores son, entre otros, la inequidad o injusta distribución del ingreso y de la riqueza, la precariedad del capital social y la desigualdad o la exclusión en las relaciones de intercambio.

La inequidad económica o desigualdad social impide casi a la mitad de todos los habitantes de Latinoamérica alcanzar las condiciones materiales para vivir con dignidad y alcanzar el ejercicio efectivo de sus derechos. El neoliberalismo, hoy día, al oponerse a la intervención redistributiva del Estado, perpetúa y acrecienta la desigualdad socioeconómica tradicional. El neoliberalismo introduce el criterio de que solamente el mercado posee la virtud de asignar eficientemente los recursos y fijar a los diversos sectores sociales los niveles de ingreso. Se abandonan así los esfuerzos por alcanzar la justicia social mediante una estructura progresiva de impuestos y una asignación del gasto público que privilegie a los más desfavorecidos, dejando de lado los intentos por la democratización de la propiedad accionariada o la reforma agraria integral.

Al mirar el capital social en nuestros países se encuentra que la oferta educativa es escasa y de baja calidad para más de la mitad de los pobladores. La inversión en ciencia y tecnología es marginal en la mayoría de los presupuestos. Las condiciones de salud son malas. Hay un inmenso vacío de infraestructura para la mayoría de hogares pobres urbanos o rurales. Avanza la destrucción de la riqueza natural y al ponerse en marcha los procesos de descentralización administrativa se evidencia una fragilidad en las instituciones locales. Podría decirse que siempre los pobres en América Latina han vivido este vacío de capital social, pero se agrava con las políticas neoliberales en favor de la iniciativa privada.

El mercado, como expresión histórica de la necesidad de apoyarnos y ayudarnos unos con otros, ni es buena ni es mala, ni es capitalista ni es socialista. Como todo tipo de relación, el mercado puede ser empleado perversamente para destruir a las personas y los pueblos. El desafío no es destruir la relación de intercambio, sino ponerla al servicio 
de la realización del ser humano en armonía con la creación; colocarla dentro de un marco de condiciones de igualdad de oportunidades básicas para todas las personas, liberándola de las fuerzas de dominación y explotación que llegaron a tergiversarla en el modo de producción que se ha generalizado en occidente (SRS,28).

Los llamados capitales golondrinas, en un mercado financiero sin restricciones, se mueven sin otro propósito que aprovechar ventajas en los sistemas bancarios y monetarios, y pueden desestabilizar completamente cualquier país, produciendo efectos devastadores aun sobre las economías más fuertes latinoamericanas. Los efectos del mercado sin control social han sido particularmente graves para los pobladores rurales, donde se sintió duramente el golpe de la apertura que sacó de la producción a millones de campesinos, donde la falta de capital social es mucho más profunda. En consecuencia, al mirar a la región en conjunto, se descubre que las políticas neoliberales profundizan problemas estructurales que están en la base de la pobreza: "la distribución de la riqueza, el capital social y las distorsiones sociales generadas por el mercado cuando actúa sin control social"...

A modo de introducción al Plan de nación conviene abrir las ventanas a los testimonios, reflexiones y juicios de valor que nos llegan de diversas esquinas del mundo. El Plan de nación es un tanto geográfico y detallista de los problemas por resolver, y ello es normal porque se concentra en nuestra nación. Se nos advierte que aquí está latente una discusión ideológica y doctrinaria, que requiere claridad en el debate de estos temas. La claridad nos viene de la historia real de nuestro continente y de nuestro mundo circundante. Los testimonios y las reflexiones, brevemente integradas en este artículo introductorio, nos pueden ayudar a buscar esa claridad. Es normal que haya debate en este proceso de concertación porque la concertación nace —así se dijo- de un resultado electoral, 1997. El debate necesita un hilo conductor: "las sociedades prósperas son las que existen en función del ser humano".

\section{Plan de nación y desarrollo}

\subsection{Una concepción multidimensional del desa- rrollo}

A nuestro juicio, el documento señala correctamente que el nudo gordiano de El Salvador es la

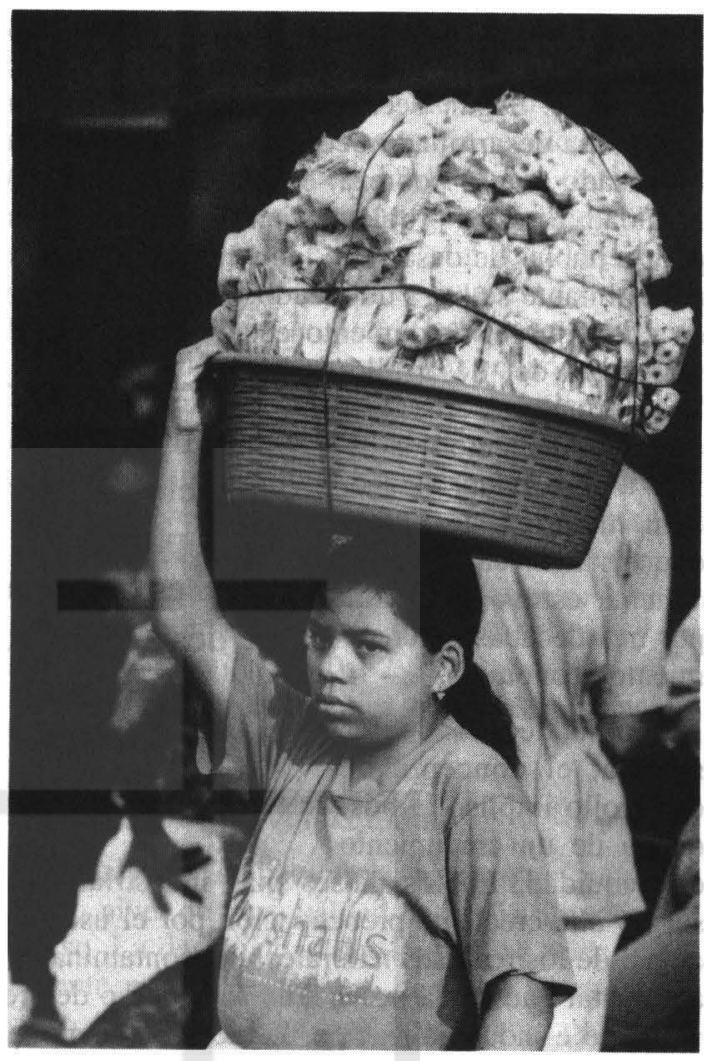

pobreza estructural. El gran reto es cómo iniciar un proceso de desarrollo incluyente, que combata en forma efectiva la pobreza y la exclusión social en nuestro país. El punto de partida de este proceso es un nuevo concepto de "desarrollo" de carácter multidimensional, tal como lo señala la Comisión, cuya importancia se comprende a partir de la evolución que ha tenido dicho concepto. De ello trataremos en los párrafos siguientes.

En la década de los cincuenta, el desarrollo se entendió prácticamente como un sinónimo de crecimiento económico e industrialización. El ser humano fue considerado como un factor más de producción, es decir, como un medio para alcanzar un crecimiento económico mayor. El indicador por excelencia del desarrollo fue el ingreso por habitante. Además, se consideró que existía un solo camino al desarrollo y que el modelo era Estados Unidos. Estas ideas se convirtieron en las dominantes a la hora de hablar del desarrollo de un país.

En la década de los sesenta se cuestionó la anterior concepción de desarrollo. El profesor 
Dudley Seers formuló con claridad la crítica a un concepto de desarrollo reducido al crecimiento económico. Según Seers, si queremos saber si un país se ha desarrollado debemos preguntarnos qué ha pasado con la pobreza, el desempleo y la desigualdad. Si estos problemas han empeorado no se podría hablar de desarrollo, aun cuando el ingreso por habitante se haya duplicado. Por lo tanto, queda claro que el crecimiento económico no puede ser el fin del desarrollo.

Es importante resaltar que el documento nos invita a no olvidar la lección histórica: la guerra que vivimos en los años ochenta estuvo precedida por tres décadas de crecimiento económico.

En la década de los setenta, el concepto de desarrollo implicó la búsqueda de un crecimiento con equidad. En los países más industrializados surgió una creciente preocupación por el uso irracional de los recursos naturales y la contaminación ambiental que había provocado su proceso de crecimiento e industrialización. Lamentablemente, en los ochenta, la recesión de la economía internacional, la explosión del problema de la deuda externa y los problemas inflacionarios llevaron a que los objetivos económicos centrales fueran la estabilidad macroeconómica y la recuperación del crecimiento económico. La década de los ochenta e inicios de los noventa fueron los tiempos de los programas de estabilización y ajuste económico. Estos procesos de ajuste agravaron los problemas de la pobreza, la desigualdad, la exclusión social y el deterioro ambiental, prácticamente en todos los países subdesarrollados.

En la década de los noventa, se consolida un nuevo concepto de desarrollo, que es denominado "desarrollo humano sostenible". Se entiende que el desarrollo significa crecimiento equitativo y en armonía con la naturaleza. En esta nueva concepción, el ser humano es el fin del proceso de desarrollo. Se trata de articular un proceso participativo, en el cual las personas deben ser sujetos y no objetos de su proceso de desarrollo. Se reconoce que el proceso de desarrollo es de carácter multidimensional, es decir, que comprende lo económico, social, político, cultural e institucional.
También se reconoce que cada pueblo puede definir su propia ruta hacia el desarrollo de acuerdo con su cultura y valores. Más aún, sería irracional aspirar a alcanzar el estilo de vida de los países llamados desarrollados con sus niveles de consumo, ya que el medio ambiente del planeta no to soportaría. Esto último implica que el estilo de vida de los países "desarrollados" no es universalizable y, por tanto, no es ético proponérselo como modelo de sociedad. Es necesario buscar un proceso de desarrollo que garantice a las mayorías la satisfacción de sus necesidades básicas y gozar plenamente de sus derechos humanos fundamentales. El documento $B a$ ses para el plan de nación contiene esta nueva concepción de desarrollo.

3.2. Principales desafios económicos para alcanzar un desarrollo humano sostenible

\subsubsection{Incrementar la tasa de crecimiento del Producto Interno Bruto}

El crecimiento económico no es el fin del desarrollo pero es una condición necesaria para alcanzar mayores niveles de vida. En El Salvador, el Producto Interno Bruto (PIB) ha crecido a una tasa promedio del 3.2 por ciento y el producto por habitante a una tasa promedio de 1.07 , desde 1950 hasta 1996 (Trigueros, A. El crecimiento económico en El Salvador de 1950 a 1996, inédito).

Si la tendencia de crecimiento del producto por habitante se mantiene a 1.07 por ciento nos tomaría aproximadamente 65 años para duplicar el producto por habitante en el país. En 1996, el producto por habitante al año se estimó en 2,653 dólares, lo que significa aproximadamente 1,923 colones al mes por persona.

Si lográramos que el PIB creciera en promedio al 7 por ciento y suponiendo una tasa de crecimiento de la población del 2 por ciento, el producto por habitante se duplicaría en 14 años. El problema es cómo dar el salto del 1.07 por ciento del producto interno bruto por habitante al 5 por ciento.

Los bajos niveles de inversión y ahorro interno como proporción del Producto Interno Bruto son 
un obstáculo para crecer a una tasa mayor, por ejemplo a un 7 por ciento, y en forma sostenida. En 1996, la inversión nacional fue de 15 por ciento del PIB y el ahorro nacional bruto, incluyendo las remesas, fue de 13.8 por ciento del PIB. Si calculamos el ahorro interno como la diferencia entre el Producto Interno Bruto y el consumo nacional, el ahorro interno es de sólo un 3 por ciento del PIB. Las economías más dinámicas del este asiático han mantenido tasas promedio de ahorro de 35 por ciento del Producto Interno Bruto. Por tanto, es claro el desafío de incrementar el ahorro y la inversión nacional para poder aspirar a tasas más altas de crecimiento económico. Especialmente, el país requiere incrementar su inversión en educación cuyos niveles se encuentran todavía por debajo de los promedios de América Latina y mundiales.

La necesidad de modernizar no sólo al sector público sino también al sector privado es otro gran desafío para aspirar a un crecimiento económico mayor. Existe un consenso que el sector público es burocrático e ineficiente, lo que constituye un alto costo de ineficiencia para la economía salvadoreña. Sin embargo, el sector privado también necesita modernizarse para enfrentar la creciente competencia internacional. Según Melhado, la economía salvadoreña se encuentra en la transición de ser una economía de agroexportación y de sustitución de importaciones a una economía abierta y moderna. Lo anterior exige que el sector privado, sobre todo la mediana y gran empresa, que ha estado acostumbrado a una cultura de hacer negocios por medio de contactos personales $\mathrm{e}$ influencias en el gobicrno, se adapte a reglas de competencia neutrales y despersonalizadas, lo que constituye un importante desafío al sector privado como principal actor del crecimiento (Melhado, O., El Salvador: retos económicos de fin de siglo, El Salvador, UCA Editores, pp.46 y 77).

La correlación posiliva entre el nivel de apertura de una economía y su tasa de crecimiento económico ha sido demostrada por diversos estudios empíricos. Lo anterior no significa que una apertura económica radical sea la mejor vía para estimular el crecimiento económico. Consideramos que la estrategia de crecimiento debe encaminarse a una apertura gradual que vaya acompañada de la identificación y promoción de industrias o sectores que sean claves en términos de generación de empleo, generación y difusión del progreso técnico e incremento de la productividad. De lo que se trata es de potenciar un polo endógeno de crecimiento con orientación hacia el exterior. En este orden de ideas, es importante destacar que el documento Bases para un plan de nación establece la necesidad de identificar áreas o sectores económicos que puedan ser los nuevos ejes del crecimiento y de nuestra inserción al mercado internacional de conformidad a los siguientes criterios: "los efectos multiplicadores sobre el resto de la economía, las oportunidades de inversión, las oportunidades de empleo, el logro de equilibrio sectoriales, la integración económica de los territorios del país y las ventajas competitivas" (p. 29). Lo anterior exige una planificación económica orientada por las señales del mercado.

\subsubsection{Crecimiento con equidad}

El Salvador se caracteriza por ser un país con un alto nivel de desigualdad en la distribución del ingreso. La desigualdad del ingreso se mide generalmente por el coeficiente de Gini. El rango de este coeficiente es de cero a uno. Un coeficiente de ccro representa una distribución del ingreso totalmente equitativa y un valor de uno la desigualdad total. El Salvador tiene el coeficiente de Gini (0.53) más alto que el de los países que tienen el mismo nivel de ingreso per cápita, lo que indica que nuestro país tiene un grado mayor de desigualdad en el ingreso que los países que tienen niveles similares de vida (Glower, C., "La econo-

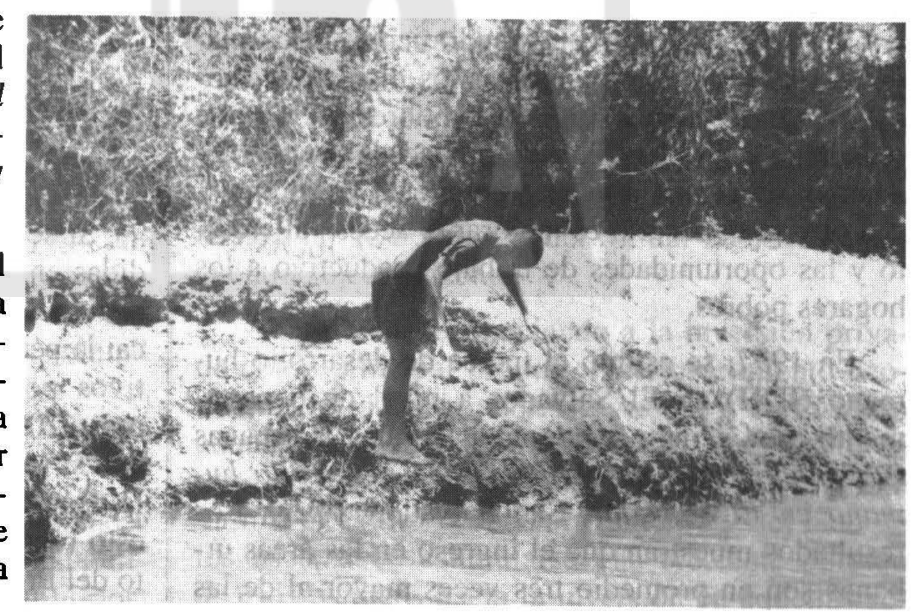


mía salvadoreña: evaluación para la modernización y el desarrollo humano sostenible" en Gobernalidad y desarrollo humano sostenible en El Salvador, San Salvador, FUCAD, 1997, p. 118).

En El Salvador, la desigualdad en la distribución del ingreso entre 1977 y 1991 se ha incrementado. Por una parte, el 10 por ciento de la población más pobre recibió el 2.1 por ciento de todo el ingreso generado en 1977, y sólo un 0.98 por ciento en 1991. Por otra parte, el 10 por ciento de los hogares de más altos ingresos recibió el 30.1 por ciento de todo el ingreso generado en 1977, y su participación aumentó a 38.4 por ciento en 1991 (Glower, p. 119).

Un estudio reciente demuestra que los altos niveles de desigualdad limitan el nivel de crecimiento económico (Birdsall, N. et. al., Desigualdad, ahorro y crecimiento económico, versión resumida en Políticas de Desarrollo, BID, marzo de 1996). Este estudio destaca que cuando los sectores pobres no pueden obtener crédito les resulta imposible financiar inversiones incluso de muy alto rendimiento; además, sus condiciones de pobreza no les permite disminuir su consumo para financiar las inversiones. Ante esta situación, si el retorno al trabajo de un hogar pobre fuera lo suficientemente alto, la respuesta racional sería trabajar más cuantitativa y cualitativamente para generar un ingreso adicional que podría destinar a la inversión. De ahí que, los autores del estudio en mención recomiendan seguir una estrategia de crecimiento aperturista que genere una alta demanda de mano de obra en los hogares pobres. Esto puede producir el doble efecto de incrementar el rendimiento del factor trabajo y brindar la oportunidad a los pobres de invertir con alto rendimiento. El corolario es que si se logra aumentar los niveles de ahorro e inversión en los sectores pobres se lograría reducir la pobreza y la desigualdad del ingreso, y además se estimularía el crecimiento económico. Así otro gran desafío es mejorar el acceso al crédito $y$ las oportunidades de trabajo productivo a los hogares pobres.

En 1997, se estimó el índice de desarrollo humano (IDH) en El Salvador a nivel de departamento, por género y por áreas rurales y urbanas (PNUD, Informe sobre índices de desarrollo humano en El Salvador, San Salvador, 1997). Los resultados muestran que el ingreso en las áreas urbanas son en promedio tres veces mayor al de las áreas rurales. La incidencia de la pobreza es mucho mayor en las áreas rurales que en las urbanas. Según cifras oficiales de 1996, la pobreza rural afecta al 64.8 por ciento de los hogares; mientras que la pobreza urbana afecta al $\mathbf{4 2 . 3}$ por ciento de los hogares. De ahí que, el Desarrollo Rural es otro gran desafío para alcanzar un desarrollo sostenible.

La mayor diferencia en niveles de desarrollo es entre departamentos extremos. Por una parte, los índices de desarrollo humano de los departamentos de Morazán, Cabañas y La Unión los coloca al nivel de los países africanos como Guinea Ecuatorial, y muy cercano a lo bajos niveles del desarrollo de Haití. Por otra parte, San Salvador está por encima del promedio nacional y se encuentra arriba de un país como Perú. Esto nos indica otro gran desafío que es el desarrollo regional y local.

El IDH reveló que, en promedio, los hombres reciben el doble del ingreso que perciben las mujeres, y que las diferencias se hacen mayores en los departamentos que tienen un nivel de IDH más alto. Esto nos muestra la importancia de introducir la perspectiva y la política de género al combatir los problemas de la pobreza y la desigualdad económica.

\subsubsection{Crecimiento económico en armonía con el medio ambiente}

Un estudio reciente patrocinado por FUSADES realizó una estimación aproximada del costo de la degradación ambiental en el país (Panayotou, T; Faris, R. y Restrepo C., El desafío salvadoreño: de la paz al desarrollo sostenible, mayo de 1997). Esta estimación incluye las pérdidas en concepto de salud derivadas de la contaminación del agua y el aire; la disminución en la productividad del suelo y la sedimentación de los embalses. El costo conservador de lo anterior está en el rango de 300 a 400 millones de dólares anuales (Panayoutou, p. IV).

Si se contabilizaran otros costos como las pérdidas en las zonas pesqueras debido a la contaminación del agua y a la sobreexplotación de la pesca; la pérdida de turismo y de los beneficios recreativos potenciales, las pérdidas estimadas serían otros 200 millones de dólares. El estudio destaca que si tomamos como un total parcial del costo de la degradación ambiental 500 millones de dólares, esto representaría aproximadamente el 5 por ciento del Producto Interno Bruto (Panayotou, p. iv). 
Si en los pasados cinco años el crecimento económico promedio ha sido aproximadamente 6 por ciento, significa que las ganancias del crecimiento económico apenas logran compensar las pérdidas por la degradación ambiental. Lo anterior sin tomar en cuenta el crecimiento poblacional. Esto nos demuestra que el patrón de crecimiento económico de nuestro país no es sostenible. Sin lugar a dudas, necesitamos de una ley efectiva del medio ambiente que pueda regular los abusos que los agentes de la actividad económica cometen contra la naturaleza.

\subsection{Estabilidad macroeconómica y desarrollo sostenible}

Desde inicios de la presente década se ha planteado la estabilidad macroeconómica como condición necesaria pero no suficiente para el desarrollo económico. Esto significa que, en última instancia, la formulación de la política macroeconómica a corto plazo debe supeditarse a los objetivos terminales del desarrollo económico. Tal enfoque parece ser reconocido en Bases para el plan de nación, en términos de lograr acuerdos —en torno a los medios y fines de la gestión macroeconómica- - "que favorezcan el dinamismo de los diferentes sectores productivos en el mediano y largo plazo" (Comisión Nacional de Desarrollo, Bases para el plan de nación, San Salvador, enero, 1998).

En prospectiva, se perfila el desafío de conciliar los objetivos e instrumentos de la estabilización macroeconómica con las demás dimensiones del desarrollo: crecimiento, equidad y sustentabilidad ambiental. Dada la complejidad de las interacciones entre esas facetas, la estabilidad macroeconómica requiere ampliar su connotación tradicional, la cual otorga privilegio a la estabilidad inonetaria. Al respecto, sugiere Rosenthal: "La estabilidad macroeconómica no se limita a una baja inflación y al equilibrio fiscal; también supone un déficit sostenible en cuenta corriente un nivel de ahorro interno que permita realizar inversiones, un tipo de cambio real adecuado y un nivel de demanda agregada congruente con la plena utilización de la capacidad de producción existente" (Rosenthal Gert, "La evolución de las ideas y las polílicas para el desarrollo", Revista de la CEPAL No 60, diciembre, 1996, Santiago de Chile, 1997).

Como punto de partida, se requiere comprender los vínculos entre los componentes de la estabilidad macroeconómica: macroprecios y equilibrios.
El primer grupo comprende el nivel general de precios (mercado de bienes y servicios), el tipo de cambio (mercado de divisas), el tipo de interés (mercado de capitales) y el nivel de salarios (mercado de trabajo). El segundo conjunto incluye los equilibrios internos (máximo empleo y equilibrio fiscal) y el equilibrio externo (balanza de pagos). Por tanto, la consistencia entre los macroprecios y los equilibrios —en cuanto a instrumentos y objetivos- se presenta simultáneamente con la articulación de la estabilización al crecimiento y la equidad.

A manera de identificar los planteamientos de las Bases para el plan de nación en torno al crecimiento y equidad y relacionarlos con algunos elementos de la estabilización, se presenta el resumen siguiente:

\section{Crecimiento Equidad}

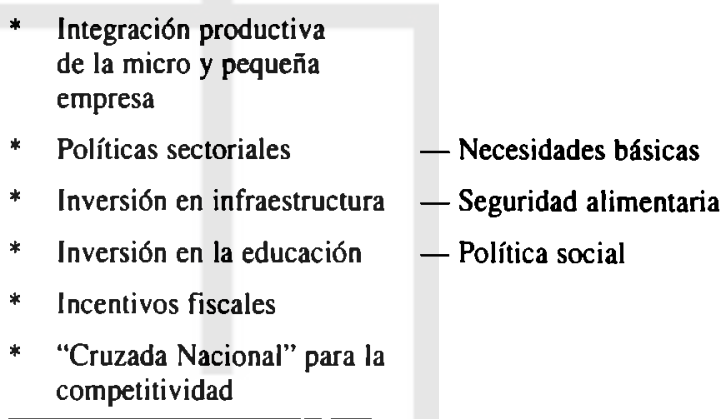

La síntesis anterior revela una serie de acciones tendientes a un grado notable de "activismo" por parte del sector público, en contraste con la actual tendencia a comprimir su tamaño. Precisamente en este aspecto algunos programas de ajuste y estabilización al conceder prioridad al equilibrio fiscal a corto plazo, han sacrificado la inversión en infraestructura económica y social. Sin embargo, resulta alentador que en las Bases para el plan de nación la "Redefinición del rol del Estado" se encuentra sujeta a debate.

Ahora bien, reconociendo a la inversión privada como principal propulsor del crecimiento económico, el balance ahorro-inversión a corto plazo adquiere especial significación. Desde el punto de vista de las fuentes de financiamiento, se requiere un mayor esfuerzo de ahorro interno y del lado de los usos, debe estimularse una creciente porción de esos recursos hacia la inversión en aquellas ac- 
lividades que se identifiquen con las "áreas prioritarias de desarrollo", según las Bases para el plan de nación. Evidentemente, aquí se plantea otro desafío: ¿cómo lograr que el sistema financiero ejecute esa intermediación en función de las necesidades de inversión en esas áreas prioritarias?

En ese sentido, en las Bases para el plan de nación se proponen ciertos compromisos para el sistema financiero y la reestructuración del Banco Multisectorial de Inversiones. En tanto dichos compromisos no sean asumidos sigue en vigencia esa interrogante en el actual contexto macroeconómico.

Con todo, las Bases para el plan de nación dan la pauta para retomar algunas de las lecciones de los programas de ajuste y estabilización en otros países. En la mayoría de los casos - El Salvador no es la excepción-, los éxitos de la estabilización se han conseguido a expensas del crecimiento $y$ de la equidad.

\section{El rol del Estado y la reforma social}

\subsection{La orientación de las funciones del Estado}

En las Bases para el plan de nación se establecen tres aspectos propios de la naturaleza del Estado. Se percibe a éste como regulador, subsidiario y garante o gestor de la actividad pública² ${ }^{2}$.

En cuanto regulador le compete la función básica de establecer un marco regulatorio a partir del cual se susiente el desarrollo del país en el mediano y largo plazo. Tal función supone, en primer término, la eliminación de algunas ambigüedades plasmadas en la Constitución Política de la República, además de la definición de las atribuciones y responsabilidades del Estado de manera consensuada, particularmente las referidas a su papel en la asignación de recursos, la orientación de la inversión, los énfasis de política sectorial, el control de la delincuencia, el aumento en la credibilidad del sistema judicial y el tema sensible de la seguridad jurídica.

Implícitamente se admiten avances y discrepancias de los distintos sectores sociales respecto a la orientación de tal atribución, no obstante es evidente que las Bases para el plan da nación aluden a un mínimo que el Estado deberá redefinir en su función reguladora. Para tal efecto hará falta que los distintos sectores de la sociedad civil definan su participación complementaria en aquellas áreas en las que el Estado por definición estaría fuera. En todo caso, el horizonte está plantcado el cual intenta superar cl definido problema principal de pobreza en el país.

En cuanto a la naturaleza subsidiaria que corresponde al Estado, en el documento de las Bases para el plan de nación se acepla que éste debe prestar a la población ciertos servicios hásicos. La discusión nuevamente que debicra resolver la sociedad es, en primer lugar, definir qué se entenderá por servicios básicos, el número, el lipo, la calidad, la relación costo-beneficio que reportará, la manera de producción del servicio, cómo se linanciará, etc. Qué argumentos sustentan el planteamiento de que "por naturaleza deben" ser prestados por el Estado. En segundo lugar, un aspecto en cuya discusión se ha avanzado mucho, no por el peso de los argumentos sino más bien por razones financieras, el cual tiene que ver con la cobertura de los servicios básicos.

De hecho, en la mayoría de programas y proyectos sociales existentes se ha optado por un criterio de focalización ${ }^{3}$. El argumento más contundente sobre esta opción radica en la limitación de recursos financieros disponibles para el caso ${ }^{4}$. En efecto, ambos aspectos deberán ser retomados por la sociedad y ser resueltos de manera creativa, comprometida y realista.

En cuanto a la función de garante, se reconoce que el impulso y la estabilidad del desarrollo son posibles si el Estado es capaz de garantizar la seguridad jurídica y la propiedad. Ningún país puede cifrar realistamente sus esperanzas de progreso si no cuenta con la seguridad jurídica que inspire credibilidad y respeto al derecho ajeno. La reactivación económica y su consolidación, especialmente si están orientadas a la captura de mercados externos, pasan por la presencia de expectativas favorables a la inversión tanto nacional como ex-

2. Bases para el plan de nación, p. 22.

3. Por ejemplo, el Fondo de Inversión Social (FIDLD), lo que fuera la Secretaría de Reconstrucción Nacional (SRN), gran cantidad de recursos de los Ministerios de línea como Salud, Educación, Obras Públicas o el Programa de Vivienda Popular, son casos en donde lo que se privilegia es el criterio de Focalización y no el de Universalidad.

4. Constantemente organismos como el PNUD, Banco Mundial y BID han argüido que en países latinoamericanos o de otras latitudes en donde los esfuerzos por erradicar la pobreza han sido más fructíferos, el índice de tributación 
tranjera. Dentro de csas expectativas, la seguridad jurídica es vital. Así mismo, los procesos de reconversión tecnológica cobran gran importancia para asegurar el acceso a mercados externos. No obstante, un hecho de importancia capital radica en las expectativas que el país pueda generar a los potenciales socios comerciales. Si éstas son positivas, los propósitos de atracción de capitales foráneos tienen mayor posibilidad de concretarse, más allá de los simples deseos o necesidades de política económica.

\subsection{Enfasis en los esfuerzos estatales}

Las Bases para el plan de nación definen tres áreas en las que el Estado deberá centrar sus esfuerzos. La primera tiene que ver con su contribución en la promoción del desarrollo económico. La segunda, con el pleno respeto a los derechos individuales y sociales, y la tercera con su función de garantes .

La primera área está en nuestra opinión bien definida, en cuanto se le asigna al Estado una función compartida. Con ello se acepta la participación de los diversos sectores de la sociedad incidiendo y definiendo activamente en lo que cada uno tiene ventajas y experiencia para promover y alcanzar el desarrollo. Es interesante advertir que la noción de desarrollo ya no es atribución principal del Estado sino que éste deberá establecer un conjunto de condiciones que propicien aquel. Esto supone un avance en la concepción de las funciones del Estado por cuanto se delinean con mayor realismo las posibilidades no sólo del Estado mismo sino de cada uno de los actores sociales. Sin embargo, debe señalarse que la posibilidad de participación de otros actores no asegura en sí misma que ésta será efectiva. Los logros del que fuera el Foro Nacional de Concertación Económica y Social pueden recordarse con los dedos de una mano. Por lo tanto, se advierte que si bien la concertación es necesaria su sola evocación no es garantía de nada en materia económica y social.

Así mismo, las atribuciones concedidas al Estado en el área de promoción del desarrollo deberán enfocarse con otros ojos. Es decir, deberán superarse los problemas típicos del Estado relacionados con la burocracia y las anomalías en la administración. También deberá quedar sentado que se requerirán esfuerzos renovados por montar la carrera de la función pública que indique precisamente los nuevos roles y las nuevas responsabilidades para poder cumplir con objetividad los nuevos desafíos.

Los roles asignados al Estado plantean el reto de la modernización del mismo articulado con una cada vez mayor participación de las distintas fuerzas sociales. Esa relación o vínculo pasa por la definición de parte del Estado de las reglas claras en las que deberá prevalecer la competencia en el mercado, es decir, el establecimiento de oportunidades para todos y no para intereses basados en formas de competencia imperfecta. Las cosas vistas así irán permitiendo la consecución al respeto de los derechos individuales y sociales plasmados en la Constitución Política. No obstante, las funciones y áreas señaladas serán quimera si los diversos actores sociales no asumen comprometidamente la tarea de formular y ejecutar el Plan de nación.

(relación tributación/PIB) sobrepasó con creces el 10.8 por ciento de El Salvador en 1997 (LPG, 14/02/98). Lo cual señala, ciertamente, un límite real de expansión del gasto o las pretensiones de inversión pública. El debate sobre este asunto es una cuestión pendiente que deberá retomarse conjuntamente entre los sectores privado y público lo antes posible.

5. lbíd., pp. 23-24. 
Cabe advertir que en las Bases para el plan de nación se van señalando diversos principios que permiten concluir que prevalece un espíritu consIructivo que pretende plantear los principios que propiciarán el desarrollo sostenible del país. Así parecen ser aspectos cruciales: (a) la presencia de una renovada concepción del papel del Estado, sobre todo si se promueve su necesaria modemización; (b) se trasluce una concepción de pluralismo que podría señalar el camino de la consolidación de la democracia y la cada vez mayor tolerancia política y búsqueda de la concertación, y (c) se consensa claramente el reconocimiento por impulsar el área social.

Sin duda que esos elementos constituyen un avance sustantivo en la forma de abordar la formulación del plan de nación. Señalan, por tanto, asuntos mínimos que deberán ser retomados para la articulación del sendero que allanará el camino del desarrollo para el país.

\subsection{El rol del Estado en el manejo de la políti- ca social}

Tanto en las Bases como en las encendidas discusiones para la aprobación del presupuesto general de la nación del presente año, parece existir un consenso alrededor de la ineludible responsabilidad del Estado y de la sociedad en general por invertir en el desarrollo de la persona. El acuerdo básico es que los esfuerzos dedicados al mejoramiento estructural de los niveles educativos, culturales, de saneamiento y salud pública, son condiciones indispensables y fundamentos del desarrollo. En tal sentido, no es un asunto de poca importancia el entendimiento global sobre esta prioridad.

En ánimo de aprobación de esta orientación, se sugieren algunos aspectos que ayudarían a consolidar tal visión, esto es (a) el incremento y eficiencia del gasto social; (b) la continua y cada vez más permanente participación de la comunidad en conjunto con otras asociaciones de la sociedad para la resolución de problemáticas locales y, (c) la pré- sencia de una visión que trascienda el ejercicio gubernamental hacia el planteamiento de políticas de más largo alcance ${ }^{6}$.

Las anteriores características denotan avances sustantivos en la noción de cómo definir y ejecutar la política social. Por supuesto que el proceso de transformación de un enfoque de corto plazo a una visión de más largo plazo, pasa por la adopción de un conjunto de medidas de carácter más operativo pero no por ello menos importante, esto es, la adopción de formas gerenciales, tecnologías, profesionalización y remuneración del personal enmarcadas dentro de un proceso de modernización del Estado para lograr ser eficiente en el manejo de la política social.

\subsection{Política social y económica: necesidad de una integración}

Un último aspecto que queremos enfatizar, puesto que se trasluce dentro de la visión de las Bases para el plan de nación, es el de la concepción de una unidad entre la esfera económica y la social. Lo social puede condicionar los resultados en el área económica, de ahí la opción por consolidar la reforma educativa emprendida. Así mismo se condiciona el desarrollo económico al mejoramiento social. La aceptación de la estabilidad macroeconómica como ineludible para garantizar el desarrollo sostenible ${ }^{7}$ es una muestra de esa noción que comunica ambas esferas como parte de una misma unidad.

Tradicionalmente se había visto la política social como secundaria en términos de la primacía que ocupaba la formulación de la política económica", no obstante en las Bases para el plan de nación parece existir un adecuado puente entre lo económico y lo social. En definitiva, lo que se concluye es que el documento hace patente la necesidad de una adecuada integración entre ambas esferas.

Sin duda que lo económico tiene una dimensión social, así como lo social tiene una dimensión económica. Esos binomios no sólo tienen que ser comprendidos por los diferentes actores sociales,

6. Un excelente resumen sobre estos aspectos aparece en el documento del Programa de las Naciones Unidas para el Desarrollo (PNUD), Reforma Social y Pobreza, BID, 1993, pp. 38 y ss.

7. Ibíd., p. 33.

8. De hecho, el Plan de Desarrollo Económico y Social de 1989-1994 confina la política social a la quinta y última parte del documento. Recuérdese que, entonces, una de las nociones claves que prevalecía para optar al beneficio de ciertos programa sociales era el criterio de compensación hacia los más pobres de los pobres. 
sino que deben ser asumidos desde una perspectiva que implique una participación y compromiso en el logro de objetivos y metas así planteados.

De la relación entre lo económico y lo social puede desprenderse lo más importante que compete formular y realizar tanto al sector privado como al sector público. Ahora, el reto más importante consiste en asimilar con prontitud y realismo la riqueza que emana de las Bases para el plan de nación y, lo más importante, comenzar a definir el verdadero plan que la nación salvadoreña tanto necesita para poder resolver el problema fundamental de pobreza señalado como el más importante.

Es responsabilidad de los diversos actores sociales el darle una oportunidad a El Salvador de efectuar un ejercicio democrático o de confinar un excelente documento como instrumento decorativo o como una referencia académica. La adopción de tal responsabilidad no implica exclusivamente la buena voluntad de asumirla, sino la sabiduría de seleccionar a los artífices idóneos que tal proceso requiere.

5. El desafio de integrar a la microempresa y las unidades de producción comunitaria

Cuando hablamos de microempresa nos referimos a aquellas unidades económicas que tengan hasta 10 trabajadores y que tengan ventas anuales de hasta 600 mil colones... ${ }^{9}$, en consecuencia, quedan incluidas la pequeña empresa y el denominado sector informal. En cuanto a las unidades de producción comunitaria, éstas incluyen a las cooperativas y las comunidades organizadas de repobladores, repatriados y desmovilizados.

Estos dos grandes sectores presentan muchas características distintas como también comunes, pero existe una que nos permite tratarlas como un solo bloque y ésta es que en ambos sectores se busca enfrentar la pobreza estructural mediante el autoempleo en empresas de su propiedad, las cua- les les posibilitan obtener algún ingreso monetario a fin de satisfacer sus necesidades.

Pero el que busquen enfrentar la pobreza por su propia cuenta no significa que ya hayan logrado salir de esa condición, como tampoco que sus esfuerzos sean un fracaso. Lo cierto es que ambos sectores tienen una importancia significativa en la vida nacional y cualquier estrategia de desarrollo debe tenerlos en cuenta a fin de posibilitar su consolidación y desarrollo. Así nos dice el Libro Blanco de la Microempresa:

Hay esperanza porque en la lucha contra la pobreza la microempresa, representada por miles de empresarios que producen, comercian, prestan servicios y crean empleos, ha sido exitosa. La permanencia de los empleos generados por la microempresa es evidente. Hay esperanza porque la microempresa ha demostrado continuamente su capacidad de adaptación a entornos que le son adversos, su capacidad de improvisación cuando las condiciones requieren que se obtengan resultados y hay escasez de recursos, su capacidad de innovación cuando el mercado en su expresión más cruda, exige nuevos productos y servicios, su capacidad de servir a estratos de población especialmente de bajos y medianos ingresos cuando requieren productos y servicios adecuados a un costo razonable. Pero también hay esperanza porque la microempresa ha demostrado que si se le da la oportunidad, tiene las cualidades y las condiciones que se necesitan para aprovecharlas ${ }^{10}$.

Ahora bien, para que esas esperanzas puedan ser realidad en las microempresas y las empresas comunitarias, nos parece que sería necesario modificar algunas macrocondiciones que les son desfavorables, tales como:

* Pese a los muchos esfuerzos orientados a proveer de recursos financieros a estos sujetos, aún existe un limitado acceso al mismo y en con-

9. Libro Blanco de la Microempresa, El Salvador, 1996, p.v.

10. Ibid., p. ii. 
diciones poco ventajosas, siendo ello un factor limitante para su desarrollo.

* No obstante que la tendencia es a privilegiar el mercado, para estos agentes económicos sigue siendo muy limitado el acceso a la información sobre mercados y precios, ya sea para abastecerse como para vender sus productos y servicios, lo cual los ubica en grave situación de desventaja.

* Existe un entorno muy desfavorable para estos agentes en términos de competencia, ya que la economía está dominada casi en su totalidad por estructuras monopólicas y oligopólicas, las cuales se traducen en condiciones de competencia desleal.

* Aunque las ONG's y los gremios les brindan mucho apoyo, para estos agentes aún no existe un marco institucional y jurídico adecuado, sino todo lo contrario, lejos de promoverlos, potenciarlos y apoyarlos, los obstaculiza.

* Al ser sectores marginados, no gozan de las ventajas de contar con una infraestructura básica: comunicaciones, carreteras, energía eléctrica, agua potable, etc., lo cual los imposibilita a desarrollar muchas actividades y, en otros casos, encarece los costos de producción".

* La falta de articulación intra e intersectorial encarece sus costos de producción y limita sus potencialidades de crecimiento endógeno provenientes de comerciar entre sí. Si al menos se articularan los productores con los comerciantes, obtendrían muchas ventajas ${ }^{12}$. Pero además de esos factores exógenos a las microempresas y las empresas comunitarias, existe otro cúmulo de factores endógenos o internos que dificultan su crecimiento y desarrollo, entre ellos tenemos:

* Cuando se trata de productores, ya sea microempresarios o cooperativistas, su incapacidad comercializadora es un factor cuya incidencia resulta negativa en la rentabilidad de sus unidades económicas.
* Otro factor que afecta principalmente a las unidades económicas comunitarias es su poca capacidad de gestión, manejo y devolución de créditos.

* Todas estas empresas, ya sean micro o comunitarias, poseen niveles de productividad bastante bajos, lo cual es otro factor que incide negativamente en sus procesos de desarrollo ${ }^{13}$.

Seguramente no sea necesario abundar con otros problemas que enfrentan y enuncian los microempresarios, tales como la falta de clientes, de recursos económicos, bajas ganancias y competencia excesiva, tardanza en la recuperación de créditos otorgados, etc. ${ }^{14}$, ya que los mismos de alguna manera se vinculan con los factores exógenos y endógenos previamente señalados. Preferimos mejor ocupar el limitado espacio con que contamos para referirnos a la forma en que se podría contribuir a eliminar la pobreza.

El Libro Blanco plantea muchos elementos que pueden ser extensivos a las empresas comunitarias, de allí que no haremos diferenciación alguna entre éstas y las microempresas. Así, por ejemplo, la visión de apoyo que se tiene para las microempresas calza para las cooperativas y comunidades:

El camino sugerido es la formulación de un conjunto de medidas tendientes a crear un entorno facilitador, en el cual el gobierno desempeñe un papel de guía normativo y evaluador, pero dejando la implementación y ejecución de programas de acción al sector privado y las gremiales ${ }^{15}$.

Sin embargo, nos parece que también el gobierno podría realizar otro tipo de actividades, como:

A fin de contribuir a que las comunidades en proceso de desarrollo se mantengan activas, el gobierno debe definir una política de aprovisionamientos en la cual se establezca que las comunidades con capacidad de suministrar bienes y servicios demandados por éste, sean elegidas preferentemente sobre cualquier otra em-

11. Para un mayor desarrollo de esta temática, consúltese "Entomo económico de la microempresa", p. 36 y ss., Libro Blanco, op. cit.

12. Para un mayor desartollo de lo anterior, consúltense Las premisas de la NEP, La Nueva Economía Popular, una aproximación teórica, San Salvador: UCA Editores, 1993.

13. Aquiles Montoya, Diagnóstico socio-económico de cien comunidades, inédito.

14. Ibid., p. 21.

15. Ibid., P. vi. 
presa nacional o extranjera para suministrarlos. La lógica de este planteamiento es que resulta más económico y conveniente, en términos sociales, contribuir a preservar los empleos en las comunidades que cargar con los gastos directos e indirectos que acarrearía la existencia de esas comunidades en situación de pobreza. También el contribuir a mantener funcionando las comunidades requiere de otro tipo de apoyos de parte de los gobiernos, como la autorización de manera excepcional del funcionamiento de su propio sistema financiero basado en cooperativas de ahorro y crédito y bancos comunales; la autorización de mecanismos expeditos de importación de insumos; el acceso a tecnología de punta; el apoyo en la implementación de programas agroecológicos, etc. La idea es que este sector cuente con un tratamiento especial, inclusive, se constituya en un sector privilegiado, a fin de que logre consolidarse y avance hacia su desarrollo sostenido ${ }^{16}$.

Finalmente, e inspirados en el Libro Blanco, para propiciar el abatimiento de la pobreza se hace necesario potenciar aquellas estrategias económicas de los pobres, lo cual significa: definir políticas económicas, y no meramente sociales, que apoyen y protejan las iniciativas económicas populares; realizar programas tendientes a incrementar la productividad en sus empresas; procurar modernizar las formas de gestión, producción y comercialización en las unidades económicas de los pobres; procurarles condiciones de competitividad que balanceen su situación de desventaja actual; establecer diferencias claras entre las empresas de los pobres generalmente de subsistencia y aquellas con capacidad de acumulación, aunque presenten algunas características propias de la informalidad.

\section{Conclusión}

Bases para un plan de nación gana en interés y profundidad si lo enmarcamos en un entorno mundial y en el horizonte del final de siglo. Nuestro "nudo gordiano" es al mismo tiempo nacional, continental y mundial. Un objetivo clave es la "concertación" nacional. Pero este objetivo no puede lograrse sin un previo requisito: la autocrítica. Se habla de ideologías y doctrinas, nada fáciles de conciliar. La solución posible es que todos entremos en un proceso de autocrítica de cara a los resultados históricos. Al terminar el siglo, ninguno de los grandes sistemas políticos económicos ha dado una positiva respuesta a los grandes problemas humanos, sociales y económicos, incluido el deterioro ecológico. Al terminar el siglo XX enfrentamos, en clave mayor, dos problemas heredados del siglo XIX: la proletarización y el darwinismo social, sumado todo ello al creciente contraste entre la sofisticada tecnología, con fines civiles o con objetivos bélicos, y la pérdida de valores humanos.

Los modelos económicos en boga han cortado el puente entre el crecimiento económico y el desarrollo humano sostenible. No es de extrañar este desquiciamiento cuando a lo largo del presente siglo se ha gastado tanto o más en carrera y producción armamentista que en desarrollo civil. La guerra se contabiliza y forma parte del crecimiento, pero destruye el desarrollo humano sostenible. Hemos sufrido una experiencia nacional. Cuando el Plan de nación integra cinco niveles de la convivencia social, nos viene a recordar que no pueden disociarse el desarrollo económico del desarrollo social, y que no puede hablarse de estabilidad y equilibrios macroeconómicos cuando crecen la inestabilidad y los desequilibrios sociales. Al enfatizar en el desarrollo humano sostenible invertimos el orden, fundamentando el desarrollo económico sobre el desarrollo social.

Una enseñanza profunda del Plan de nación es que para que haya un plan se requiere una planeación, un proceso concertado, incluso una institución planificadora que recoja, simultáneamente, los amplios desafíos nacionales y las propuestas realistas de solución. La planeación debe ser algo estable o perenne porque esos desafíos vienen del largo plazo y requieren respuestas a mediano y largo plazo. La planeación no pretende recrear Estados autoritarios, verticalistas, de ordeno y mando, sino crear un Estado analizador, expositor de la verdad y concertador de las soluciones. La verdadera planeación lleva al diálogo entre una administración pública, técnica y de gran sensibilidad social, que aporta la visión global, y los múltiples sectores privados, más cercanos a los problemas concretos y a las realistas soluciones. La planeación es concertación y no imposición, porque lo que se impone ni se obedece ni se hace.

16. Aquiles Montoya, “¿Es posible abatir la pobreza en el capitalismo?”, Revista ECA, enero-febrero, 1998. 
La planeación no es la última palabra; ella está sometida a un objetivo final: La Nación. Y la nación no son las fronteras, las aduanas, los ejércilos, ni los simples éxitos deportivos. La nación son dos: los seres humanos, y a ellos tenemos que agregar nuestra naturaleza, porque ellos han sido las dos víclimas de los modelos económicos en boga. Dialogamos con las Bases para el plan de nación desde el logotipo de la cumbre de Copenhague: "Las sociedades prósperas son las que existen en función del ser humano". 